\title{
EFFECTIVENESS OF SIZE FREQUENCY DISTRIBUTIONS IN REGULATING INTRASPECIFIC SPATIAL OVERLAP OF STREAM INSECTS
}

\author{
William P. KOVALAK \\ Department of Natural Sciences, University of Michigan-Dearborn, Dearborn, Michigan 48 I 28
}

Received September 26. 1979

Keywords: Benthos, intraspecific competition, niche breadth, niche overlap

\begin{abstract}
Spatial niche breadth and overlap of size groups of four species of epilithıc stream insects were studied to determine if broad size frequency distributions serve to reduce intraspecific competition for space. Mean niche overlap decreased with greater breadth of size frequency distributions for only one species (Baetis intercalarts) and did not vary in relation to population density. Similarly, the ratio of the probabilities of intergroup and intragroup encounter did not vary as a function of the breadth of size frequency distributions. Therefore, it was concluded that changes in size frequency distribution have a minimal effect on intraspecific competition for space among epilithic species. It was suggested that observed size frequency distributions may be more a function of extant environmental conditions (temperature and flow) than of previous or extant intraspecific competition.
\end{abstract}

\section{Introduction}

Hynes ( I 96I) and Macan ( I 963) hypothesized that broad size frequency distributions may act to reduce intraspecific competition for food and (or) space among benthic stream insects. Sheldon ( 1968 ) tested this hypothesis by comparing the diets of variously sized nymphs of a predaceous stonefly. Results of this study and others (e.g., Siegfried \& Knight, I 976; Kovalak, I978b) showed that the species of prey consumed did not vary in relation to predator size but prey size did. Differential prey size selection has been shown to be one means of reducing interspecific competition and increasing niche breadth (Roughgarden, 1972).

Less is known about the role of broad size frequency distributions in reducing competition for space. Bishop (1973) and Kovalak ( $1978 \mathrm{a}$ ) observed differential distributions of small and large individuals of some species which may act to reduce intraspecific competition. To further test whether broad size frequency distributions can reduce intraspecific competition, this study assessed spatial niche breadth and overlap of size groups of four species of stream insects: Baetis intercalaris McDunnough, Paraleptophlebia mollis (Eaton), Glossosoma nigrior Banks and Chimarra aterrima Hagen. The data analyzed were collected for a study of diel changes in the distribution and abundance of stream benthos (Kovalak, 1979).

\section{Methods}

Samples were collected in the Pigeon R., Otsego Co., Michigan in the vicinity of the Pigeon River Trout $\mathrm{Re}$ search Station, which has been described elsewhere (Kovalak, I976; 1978a).

Insects colonizing bricks placed in a riffle where current velocity ranged between 40 and $100 \mathrm{~cm} / \mathrm{s}$ were sampled on six dates between June and November, 1973. Forty sand cast bricks $(20.6 \times 9.8 \times 5.9 \mathrm{~cm})$ were placed in the riffle with the longitudinal axis of the bricks parallel with the direction of flow and pushed $\mathrm{I} \mathrm{cm}$ into the bottom. Bricks were exposed for colonization about four weeks before sampling.

To facilitate sampling and analysis, current velocities on the riffle were grouped into six, Io $\mathrm{cm} / \mathrm{s}$ intervals covering the $40-100 \mathrm{~cm} / \mathrm{s}$ range. Between July and August 6 samples were collected from the $40-80 \mathrm{~cm} / \mathrm{s}$ intervals whereas between August 27 and November, samples were collected from the $50-90 \mathrm{~cm} / \mathrm{s}$ intervals. On each date at least two bricks were collected at noon and at midnight from each current interval. Current velocities were measured at both sides of the bricks using a Gurley pygmy current meter (Model 625).

Samples were collected by placing a small handnet ( 156 $\mu \mathrm{m}$ mesh) immediately downstream of the bricks and then lifting them free of the bottom. In the laboratory, bricks were soaked in tepid water and organisms scraped from the brick surface with a toothbrush. Insects were separated from debris under Iox magnification and headwidth across 
the eyes was measured to the nearest $0.05 \mathrm{~mm}$ using an ocular micrometer.

Two approaches were used to divide size distributions of insects into size groups for analysis. Head capsule widths of $B$. intercalaris and $P$. mollis were broken into 8 , $0.15 \mathrm{~mm}$ intervals covering a range of $0.0-1.20 \mathrm{~mm}$. No attempt was made to have these size groups (designated I$8)$ correspond to instars. Caddisflies, however, were subdivided into instars; for both $G$. nigrior and $C$. aterrima five instars (designated $I-V$ ) were recognized.

Niche breadth (B) was estimated by

$$
\mathrm{B}=\mathrm{I} /\left(\mathrm{n}_{\mathrm{i}}^{\sum} \mathrm{p}_{\mathrm{xl}}{ }^{2}\right)
$$

where $\mathrm{n}$ is the number of resource states and $\mathrm{p}_{\mathrm{x}_{1}}$ is the proportion of size group $x$ in resource state $i$ (Levins, 1968). Niche overlap (L) was estimated by

$$
\mathrm{L}=\mathrm{n} \underset{\mathrm{i}}{\sum}\left(\mathrm{p}_{\mathrm{x} 1} \mathrm{p}_{\mathrm{yl}}\right)
$$

where $p_{x 1}$ and $p_{y_{1}}$ are the proportions of size groups $\mathrm{x}$ and $y$, respectively in resource state $i$ (Hurlbert, 1978).

To estimate niche breadth and overlap each brick was treated as a separate resource state.

\section{Results}

Niche breadth as it is used here is a measure of habitat utilization and not niche breadth in the strict sense because all species studied occurred in other microhabitats as well. Values for niche breadth (Eq. I) can range from $\mathrm{I} / \mathrm{n}$ (where $\mathrm{n}=$ number of resource states; here bricks) to I.O (Hurlbert, 1978). A value of I.O indicates that a resource (here space) is used in proportion to its occurrence in the environment (i.e., individuals were evenly distributed among the bricks). Values $<$ I.O indicate some resources are used at lower frequencies than predicted by abundance in the environment (i.e., disproportionate distribution of individuals among bricks).

Niche breadths varied among species, a mong size groups and between day and night (Table I). Over all dates, for $B$. intercalaris $80 \%$ of the niche breadths were between 0.60 and 0.90 . For $P$. mollis in June niche breadths ranged between 0.36 and 0.68 whereas from August to November $81 \%$ of the niche breadths were between 0.55 and 0.85 . For G. nigrior $61 \%$ of the niche breadths were between 0.45 and 0.75 and for C. aterrima $68 \%$ were between 0.50 and 0.80 .

For $B$. intercalaris and $P$. mollis there were no consistent relationships between niche breadth and size although the largest size groups (5-6) of $B$. intercalaris generally exhibited lower niche breadths. For $G$. nigrior niche breadth generaly increased with increasing size whereas for $C$. aterrima niche breadth generally decreased with increasing size.

Over all species and size groups, day-night changes in niche breadth generally were small $(75 \% \leqslant 0.15)$ and without apparent pattern.

Although one might expect niche breadths to change in response to changes in density and (or) size structure of the population because of changes in intergroup or intragroup competition, no such relationships were observed in the present data.

Values for niche overlap (Eq. 2) can range from 0.0 , where no resources are shared to values $>1$.0 where some resources are used more intensively than others and the preferences of the two size groups coincides (Hurlbert, 1978). Interpretation of niche overlap values is straightforward. A value of I.o indicates both size groups use each resource state in proportion to its occurrence (i.e., both size groups are uniformly distributed over the resource states). Values $<1$.o indicate the probability of intergroup encounter is less than it would be if both size groups were uniformly distributed over the resource states whereas values $>$ I.o indicate the probability of intergroup encounter is greater than it would be if both size groups where uniformly distributed over the resource states (Hurlbert, 1978).

For the four species studied here, in most cases $(79 \%)$ niche overlaps were $\geqslant$ I.o (Tables $2-5$ ). Of these, $61 \%$ were $>1.20$ reflecting the unequal distribution of individuals among bricks but more importantly showing the preferences of the size groups coincided. Most of the niche overlaps that were $<$ I.O (which indicates segregation) were exhibited by $B$. intercalaris and $G$. nigrior. For these species values $<$ I .0 typically were observed for overlap between the smallest and largest size groups.

If broad size frequency distributions act to reduce competition, one would expect niche overlap to decrease with increasing differences in size between groups. Although decreasing niche overlap with increasing differences in size were observed for B. intercalaris, $G$. nigrior and C. aterri$m a$, the pattern was not consistent. For $B$. intercalaris and C. aterrima this pattern was observed primarily for the largest size groups. 


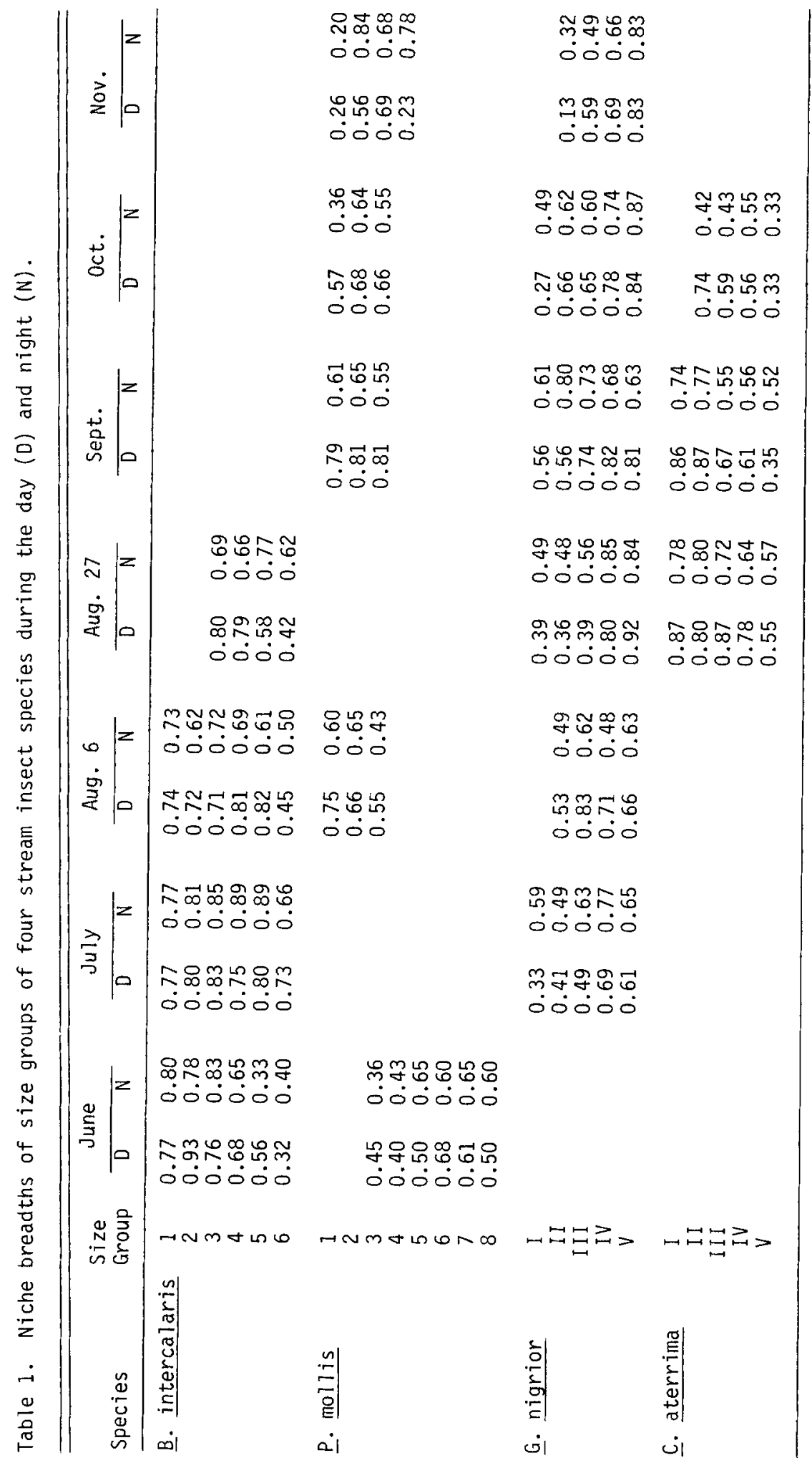


Table 2. Niche overlap of size groups 1-6 (see text) of Baetis intercalaris during the day and night.

\begin{tabular}{|c|c|c|c|c|c|c|c|c|c|c|c|c|c|}
\hline \multicolumn{7}{|c|}{ JUNE (DAY) } & \multicolumn{7}{|c|}{ AUGUST 6 (DAY) } \\
\hline & 1 & 2 & 3 & 4 & 5 & 6 & & 1 & 2 & 3 & 4 & 5 & 6 \\
\hline \begin{tabular}{l|}
1 \\
2 \\
3 \\
4 \\
5 \\
6
\end{tabular} & $\begin{array}{l}---- \\
1.09 \\
1.01 \\
0.90 \\
0.60 \\
0.60\end{array}$ & $\begin{array}{l} \\
---- \\
1.02 \\
1.10 \\
0.85 \\
1.13\end{array}$ & $\begin{array}{l}0 .-9 \\
0.93 \\
1.21 \\
1.09\end{array}$ & $\begin{array}{l}--- \\
0.96 \\
1.87\end{array}$ & 1.25 & --- & $\begin{array}{l}1 \\
2 \\
3 \\
4 \\
5 \\
6\end{array}$ & $\begin{array}{l}---- \\
1.34 \\
1.26 \\
1.07 \\
0.95 \\
0.83\end{array}$ & $\begin{array}{l} \\
---- \\
1.31 \\
1.14 \\
0.94 \\
0.95\end{array}$ & $\begin{array}{l}1.23 \\
1.02 \\
1.21\end{array}$ & $\begin{array}{l} \\
---- \\
1.11 \\
1.29\end{array}$ &.--- & $-\cdots$ \\
\hline \multicolumn{7}{|c|}{ JUNE (NIGHT) } & \multicolumn{7}{|c|}{ AUGUST 6 (NIGHT) } \\
\hline & 1 & 2 & 3 & 4 & 5 & 6 & & 1 & 2 & 3 & 4 & 5 & 6 \\
\hline \begin{tabular}{l|}
1 \\
2 \\
3 \\
4 \\
5 \\
6
\end{tabular} & $\begin{array}{l}---. \\
1.13 \\
1.12 \\
1.13 \\
1.25 \\
1.46\end{array}$ & $\begin{array}{l}---- \\
1.23 \\
0.83 \\
1.67 \\
0.92\end{array}$ & $\begin{array}{l}-\cdots \\
0.85 \\
1.61 \\
0.94\end{array}$ & $\begin{array}{l}0.30 \\
1.79\end{array}$ & 0.42 & --- & $\begin{array}{l}1 \\
2 \\
3 \\
4 \\
5 \\
6\end{array}$ & $\begin{array}{l}0--- \\
1.43 \\
1.29 \\
1.12 \\
1.17 \\
0.75\end{array}$ & $\begin{array}{l} \\
---- \\
1.36 \\
1.18 \\
1.09 \\
0.54\end{array}$ & $\begin{array}{l}---- \\
1.13 \\
1.05 \\
0.62\end{array}$ & $\begin{array}{l}1.29 \\
0.87\end{array}$ & 1.04 & --- \\
\hline \multicolumn{7}{|c|}{ JULY (DAY) } & \multicolumn{5}{|c|}{ AUGUST 27 (DAY) } & & \\
\hline & 1 & 2 & 3 & 4 & 5 & 6 & & 3 & 4 & 5 & 6 & & \\
\hline \begin{tabular}{l|}
1 \\
2 \\
3 \\
4 \\
5 \\
6
\end{tabular} & $\begin{array}{l}---- \\
1.20 \\
1.11 \\
0.86 \\
1.01 \\
1.10\end{array}$ & $\begin{array}{l}---- \\
1.17 \\
0.83 \\
1.00 \\
1.09\end{array}$ & $\begin{array}{l}--- \\
0.96 \\
0.90 \\
1.08\end{array}$ & $\begin{array}{l}-.03 \\
1.03 \\
1.17\end{array}$ & 1.16 & --- & $\begin{array}{l}3 \\
4 \\
5 \\
6\end{array}$ & $\begin{array}{l}-0- \\
1.16 \\
1.03 \\
1.11\end{array}$ & $\begin{array}{c}---- \\
1.20 \\
1.29 \\
\text { NIGHT) }\end{array}$ & 1.68 & --- & & \\
\hline \multicolumn{7}{|c|}{ JULY (NIGHT) } & & 3 & 4 & 5 & 6 & & \\
\hline & 1 & 2 & 3 & 4 & 5 & 6 & \multirow{2}{*}{$\begin{array}{l}3 \\
4 \\
5 \\
6\end{array}$} & \multirow{2}{*}{$\begin{array}{l}\overline{---} \\
1.12 \\
0.98 \\
0.98\end{array}$} & --- & & & & \\
\hline \begin{tabular}{l|}
1 \\
2 \\
3 \\
4 \\
5 \\
6
\end{tabular} & $\begin{array}{l}---- \\
1.20 \\
1.10 \\
0.83 \\
0.99 \\
0.77\end{array}$ & $\begin{array}{l}-1.09 \\
0.87 \\
0.98 \\
0.69\end{array}$ & $\begin{array}{l}---- \\
0.88 \\
0.89 \\
0.77\end{array}$ & $\begin{array}{l}---- \\
1.06 \\
1.21\end{array}$ & 1.12 & ---- & & & $\begin{array}{l}1.16 \\
0.82\end{array}$ & 1.10 & $-\cdots$ & & \\
\hline
\end{tabular}

To determine if broad size frequency distributions reduce spatial overlap, the relationship between mean niche overlap for all pairs of size groups (i.e., mean of values in overlap matrices) and an index of breadth of SFD was examined. The index of breadth of SFD used here was

$$
E=\frac{I}{n \sum_{i}^{\Sigma} p_{c}^{2}}
$$

where $\mathrm{n}=$ number of size classes and $\mathrm{p}_{\mathrm{c}}$ is the proportion of individuals in a size class. Values can range from $\mathrm{I} / \mathrm{n}$ where all individuals are in a single class to 1.0 where individuals are evenly distributed among the size classes. Values for $\mathrm{n}$ were always set at the maximum number of size classes a species can have whether or not individuals were present in that size class on a date.

Only $B$. intercalaris exhibited an inverse relationship between mean niche overlap and breadth of SFD which would suggest broad SFD can reduce intraspecific competition by reducing spatial overlap (Fig. I). For the other species there were no apparent relationships between mean niche overlap and breadth of SFD.

Measures of spatial overlap do not fully evaluate potential reduction of intraspecific competition because only the probability of intergroup encounter is used to estimate spatial segregation. For broad SFD to reduce intraspecific competition the probability of intergroup encounter must be less than the probability of intragroup encounter other- 
Table 3. Niche overlap of size groups 1-8 (see text) of Paraleptophlebia mollis during the day and night.

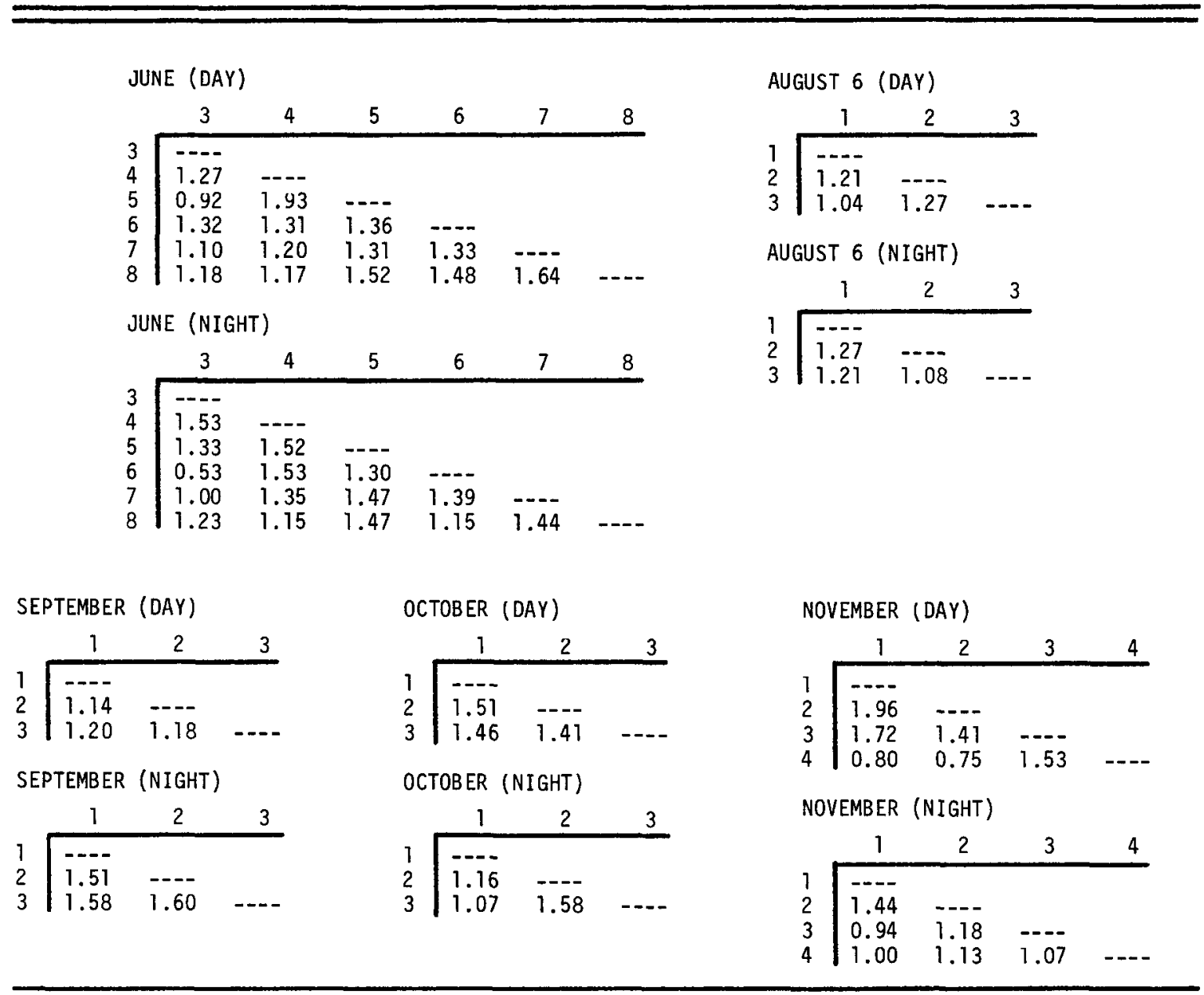

wise there would be little advantage to distributing individuals among size classes.

Ratios of probabilities of intergroup and intragroup encounter were determined from

$$
\frac{\Sigma p_{\mathrm{x} 1} p_{y 1}}{\Sigma p_{x_{1}}{ }^{2}} \text { and } \frac{\Sigma p_{x 1} p_{y 1}}{\Sigma p_{y 1}^{2}}
$$

where $\Sigma p_{x_{1}} p_{y 1}$ is the probability of intergroup encounter (niche overlap) and $\Sigma \mathrm{p}_{\mathrm{x} 1}{ }^{2}$ and $\Sigma \mathrm{p}_{\mathrm{y} 1}{ }^{2}$ are probabilities of intragroup encounter based on the niche breadths of species $\mathrm{x}$ and $\mathrm{y}$, respectively. From eqs. I and 2

$$
\frac{\Sigma p_{x 1} p_{v_{1}}}{\Sigma p_{v_{1}}^{2}}=B_{x} L_{x(y)}
$$

$\mathrm{B}_{\mathrm{x}} \mathrm{L}_{\mathrm{x}(\mathrm{y})}$ is equal to $\alpha_{\mathrm{xy}}$ of Levins ( 1968 ), which he considered an approximation of the competition coefficient based on niche overlap. Here $B_{x} L_{x(y)}$ is simply interpreted as the ratio of the probabilities of intergroup and intragroup encounter. Values can range from o where there is no niche overlap to values $>$ I.O. A value of 1.0 indicates the niche of two size groups are identical. Values greater than 1.0 are more difficult to interpret. They occur where two size groups overlap broadly in total niche dimension but where one niche is narrower than the other (Fig. 2). In Figure 2 the probability of encounter of an individual of size group $B$ with size group $A$ is greater than with another $B$ because of the broader niche of $B$.

For $B$. intercalaris, $P$. mollis and $C$. aterrima mean ratios of the probabilities of intergroup and intragroup encoun- 
Table 4. Niche overlap of instars I-V of Glossosoma nigrior during the day and night.

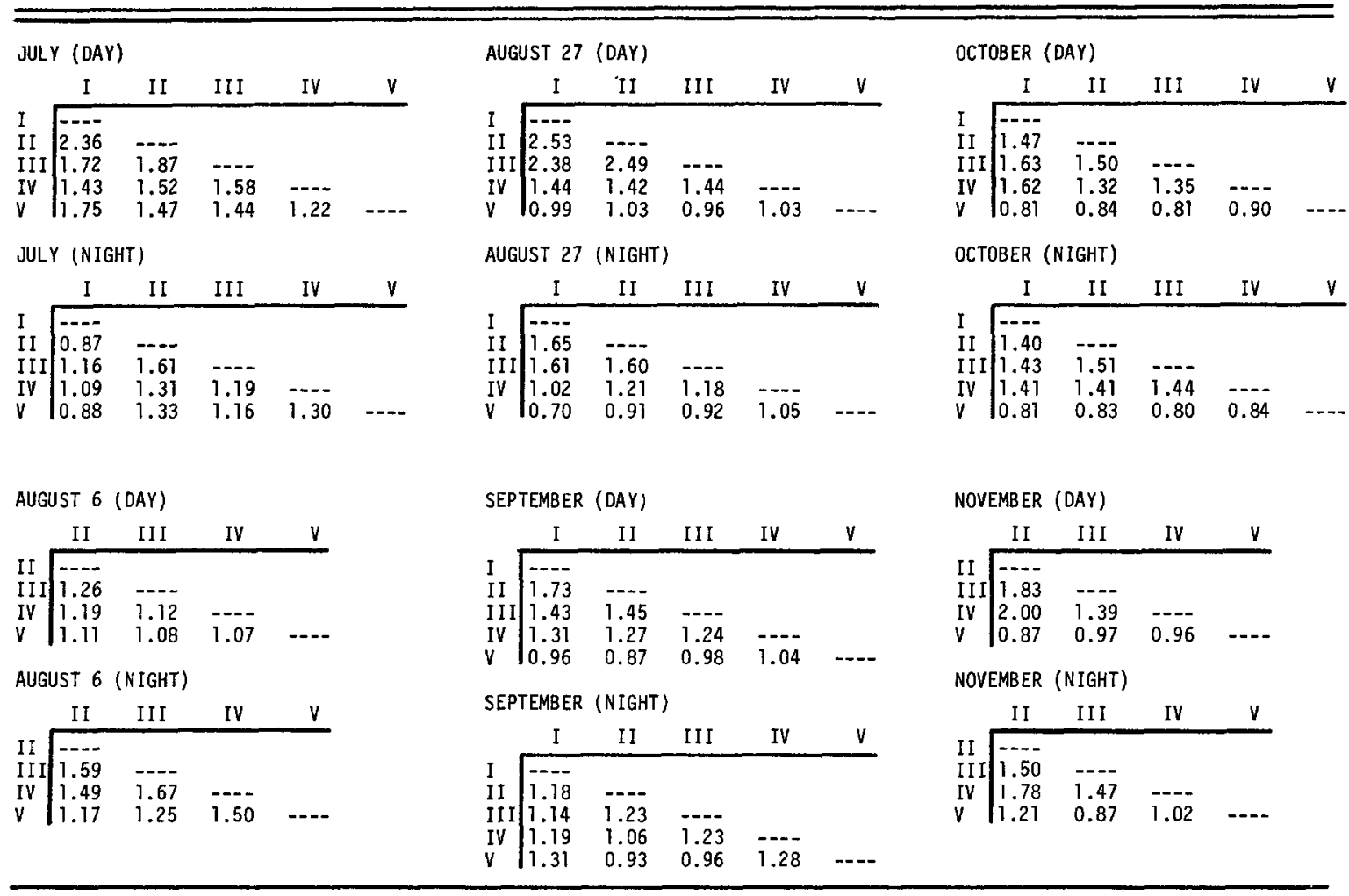

ter did not vary with breadth of SFD whereas for $G$. nigrior the variables were positively correlated $(\mathrm{P}<0.05)$ (Fig. 3). This suggests that for $G$. nigrior broad SFD increased interaction between size groups although overall interactions between individuals were less than if all individuals were the same size.

Over all dates, the range of mean ratios of probabilities of intergroup and intragroup encounter for the four species were: $B$. intercalaris, 0.69-0.8I, P. mollis, 0.6I-0.94, G. nigrior, $0.70-0.84$ and $C$. aterrima, $0.80-0.88$. These values indicate that the observed SFD yielded a $10-40 \%$ reduction in intraspecific spatial overlap.

\section{Discussion}

Niche breadths for most size groups ranged between 0.50 and 0.90 because individuals occurred on all bricks but showed preferences for specific ones. Preferences for specific bricks probably were related to current velocity preferences (Kovalak, 1975; 1979) whereas occurrence over all the bricks probably resulted from genetic differences among individuals, competition and the randomizing effects of drift.

Smaller niche breadths exhibited by $B$. intercalaris size groups 5 and 6 were related to selection of faster currents by larger nymphs (Kovalak, I975). Larger $B$. intercalaris, which presumably have a lower surface area: volume ratio, may use faster currents to facilitate oxygen uptake (cf. Hynes, 1970). The progressive increase in niche breadth with increasing size exhibited by $G$. nigrior may result from post-eclosion dispersal where eggs are laid in discrete clumps. Similarly, Cummins (1975) reported decreased clumping of $G$. nigrior larvae with increasing size. For $C$. aterrima, niche breadth decreased with increasing size. Aggregation of fifth instar larvae in restricted microhabitats may be related to active selection of pupation sites (cf. Williams \& Hynes, I973).

Niche overlap was primarily a function of niche breadth in the restricted set of resource states studied here. Because size-related differences in niche breadth of $B$. intercalaris, $G$. nigrior and $C$. aterrima were related to biological characteristics of the species (see above), low niche overlaps reported here, particularly between small and large 
Table 5. Niche overlap of instars I-V of Chimarra aterrima during the day and night.

\begin{tabular}{|c|c|c|c|c|c|}
\hline \multicolumn{6}{|c|}{ AUGUST 27 (DAY) } \\
\hline & I & II & I II & IV & $v$ \\
\hline 1 & $\because \cdots$ & & & & \\
\hline II & 1.03 & -1 & & & \\
\hline IV & 1.03 & $\begin{array}{l}1.18 \\
1.25\end{array}$ & 1.18 & A & \\
\hline$v$ & 0.88 & 1.20 & 1.20 & 1.33 & - - \\
\hline
\end{tabular}

AUGUST 27 (NIGHT)

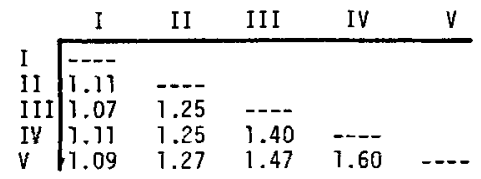

SEPTEMBER (OAY)

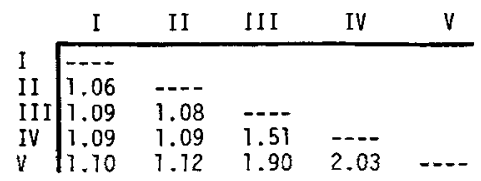

SEPTEMBER (NIGHT)

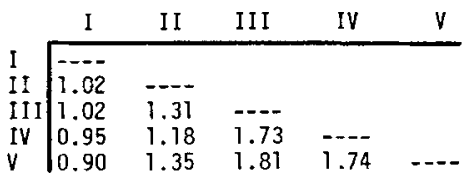

OCTOBER (DAY)

\begin{tabular}{lllll}
\multicolumn{1}{l}{} & II & III & IV & V \\
\cline { 2 - 5 } II & --25 & --- & & \\
III & 1.26 & -1.43 &.--- & \\
IV & 1.18 & 1.74 & \\
V & 1.53 & 1.74 & 1.76 & $\ldots-.-$
\end{tabular}

OCTOBER (NIGHT)

\begin{tabular}{l|cccc}
\multicolumn{1}{c}{} & II & III & IV & V \\
\cline { 2 - 5 } II & ---- & & & \\
II I & 2.25 & ---- & & \\
IV & 1.96 & 1.99 & ---- & \\
V & 2.40 & 2.43 & 2.09 & $\ldots--$
\end{tabular}

size groups, probably were not the result of previous or extant competition. Moreover, some of the low niche overlaps between small and large individuals were attributable to low population densities. At low mean densities individuals are absent from some bricks reducing apparent niche breadth and. therefore, niche overlap.

Intraspecific spatial overlap of instars of G. nigrior and C. aterrma was similar despite differences in feeding strategles of these species. Larval instars II-IV of G. nigrior feed indiscriminately on diatoms consuming all size groups in proportion to occurrence on stones (Tindall \& Kovalak,
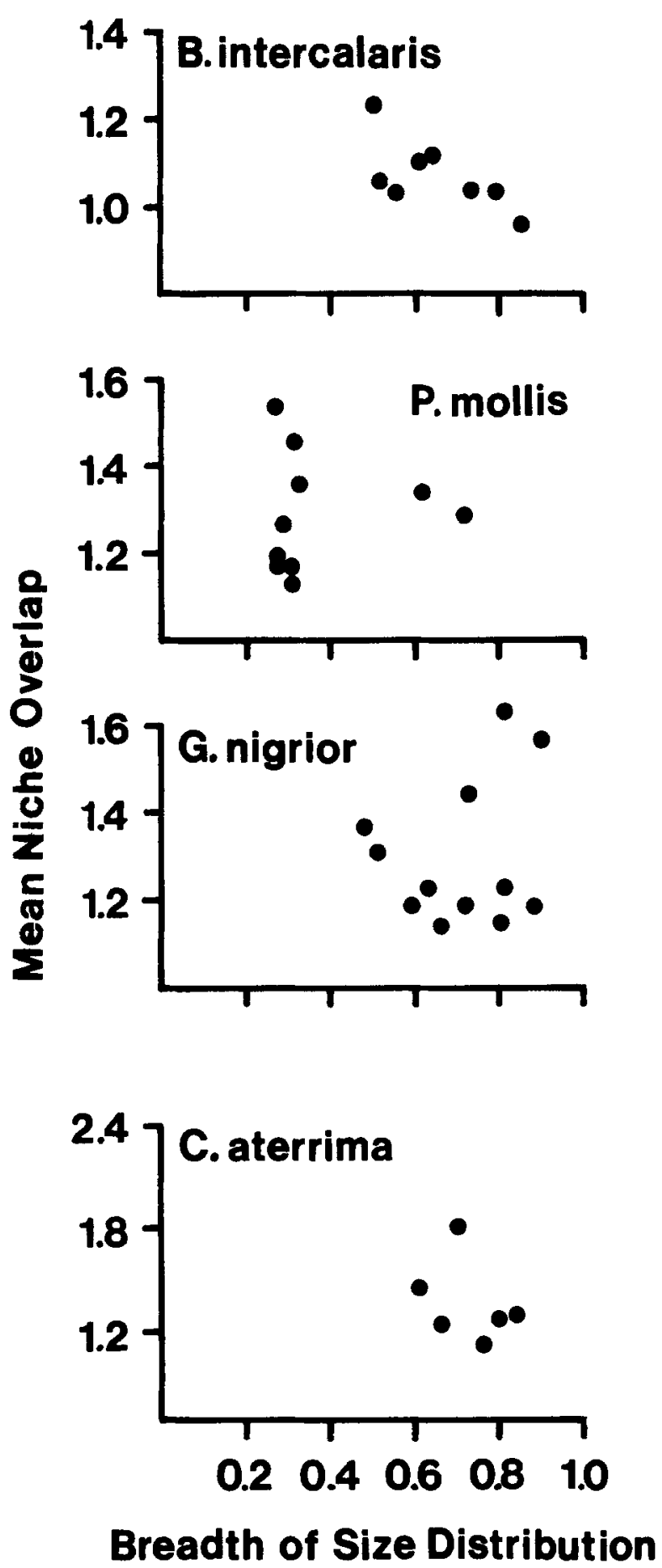

Fig. 1. Relationships between mean niche overlap of size groups of 4 species of stream insects and breadth of size frequency distribution. 


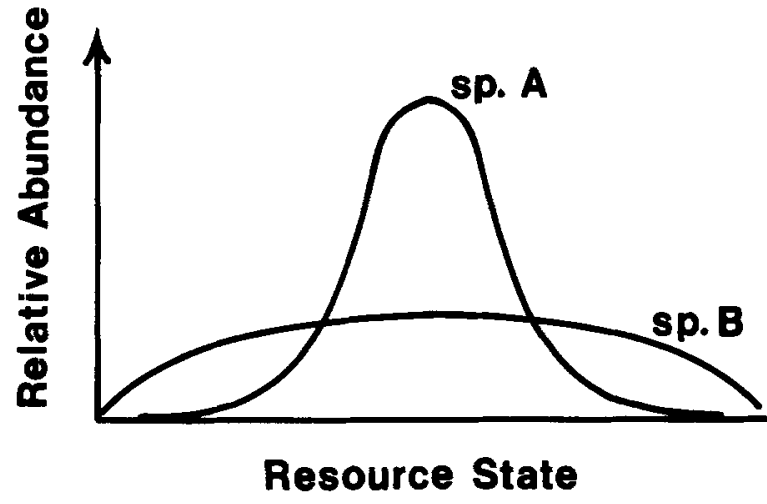

Fig. 2. Hypothetical relationships between niches of 2 size groups ( $A$ and $B$ ) of a species where the probability of intergroup encounter between $A$ and $B$ is greater than intragroup encounter of $B$.

1979). Presumably instars of C. aterrima, like other philopotamids, feed on different size particles determined by mesh dimensions of capture nets (Wallace \& Malas, 1976). Therefore, it was hypothesized that instars of $C$. aterrima could afford greater spatial overlap than instars of $G$. nigrior because of differential food particle size selection. This was not the case in this study, which suggests that food was not an important factor influencing intraspecific spatial distributions.

Because the ratio of intergroup and intragroup encounter did not vary as a function of SFD and because mean niche overlap decreased with increasing breadth of SFD in only one case (B. intercalaris) and did not vary in relation to population density, it was concluded that changes in SFD have a minimal effect on intraspecific competition for space among epilithic species. Greater spatial segregation among size groups of $B$. intercalaris may be related to active swimming behavior of the nymphs. Spontaneous swimming activity of baetid nymphs (Corkum, 1978) may reduce intraspecific interaction by facilitating avoidance responses (McLay, 1968) or by contributing to microhabitat selection (Walton et al., 1977) which as indicated earlier may be related to the respiratory requirements of the nymphs.

High niche overlaps reported here do not demonstrate conclusively that broad SFD cannot serve to reduce spatial overlap. In this study, all individuals of a species on a brick were treated together regardless of the face on which they were positioned. It has been well documented that individuals occur on all faces of stones but prefer specific faces (e.g., Scott, 1958: Moretti \& Gianotti, I962; Décamps et al., 1975) which may reflect current preferences. Insects may select specific currents to facilitate
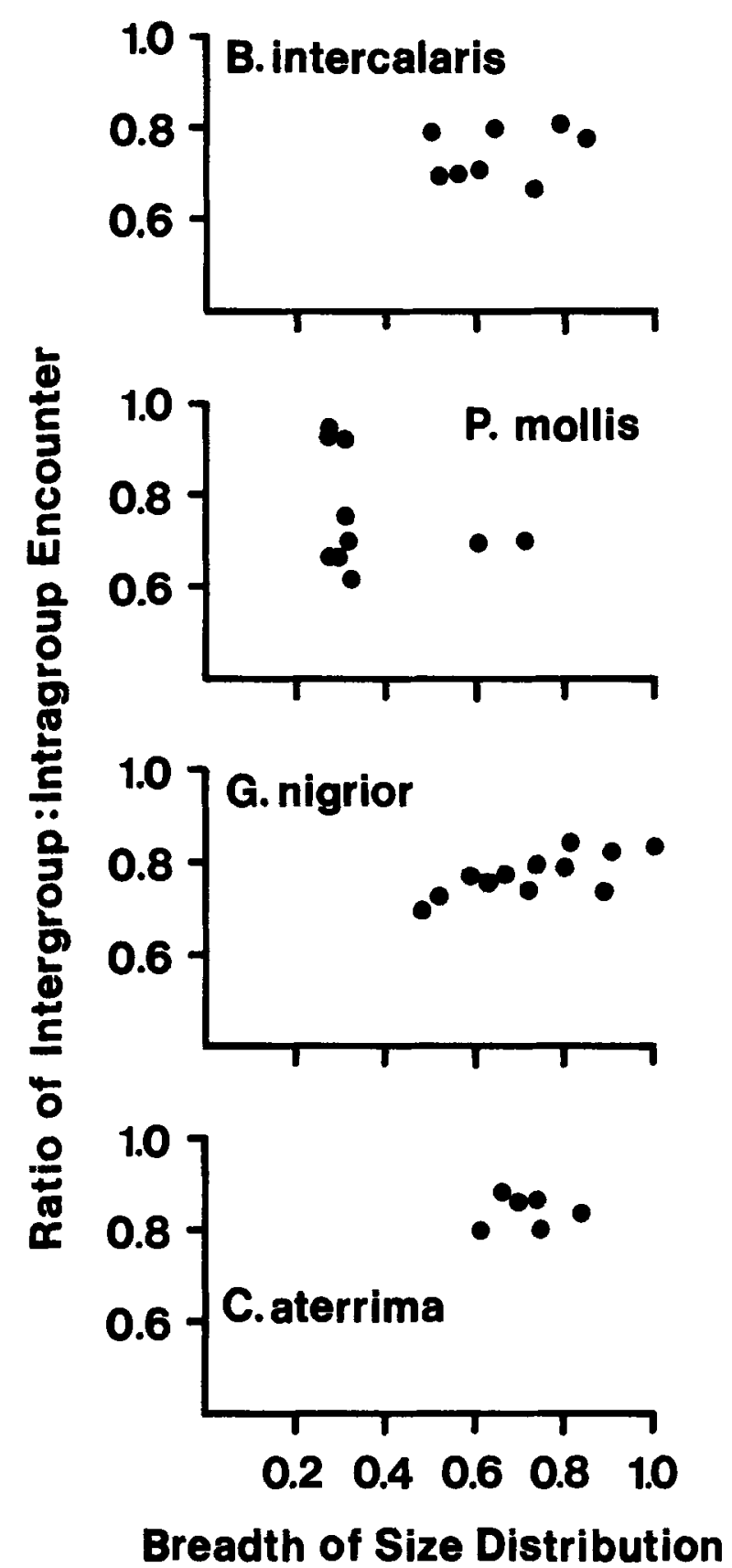

Fig. 3. Relationships between the mean ratios of the probabilities of intergroup and intragroup encounter of size groups of 4 species of stream insects and breadth of size frequency distribution. 
oxygen uptake (Hynes, 1970; Kovalak, 1976) because current renews oxygen supply at respiratory surfaces (Madsen 1968). If positioning is used to facilitate oxygen consumption then we might predict a differential distribution of large and small individuals. Large individuals which have a lower surface area: volume ratio (Istenic in Hynes. 1970) may select faster currents on exposed faces of stones because of greater difficulty in satisfying oxygen requirements. Smaller individuals, on the other hand, can occupy more current-sheltered faces because of greater surface area: volume ratios. Detection of differential distributions of size groups on stony substrates depends on sampling on a finer scale than was used here.

Broad SFD also may reduce intrspecific spatial overlap for species which occupy interstitial spaces of sediments. Because body size determines space requirements, larger individuals generally will be associated with larger spaces in coarse sediments whereas smaller individuals generally will be associated with smaller spaces in finer sediments. This pattern of space use may account for differential distributions of large and smail individuals reported by Bishop ( 1973) and for sexual dimorphism in winter stoneflies (Kovalak. I 978a).

Arguments relating SFD to previous or extant competition aside, observed SFD may simply be a consequence of environmental conditions. Ide ( 1935 ) reported that in a temperate stream synchrony of cohort development and emergence was a function of thermal regime. In thermally stable headwaters emergence and oviposition occurted throughout the summer causing asynchrony of eclosion and growth which resulted in broader SFD than in down. stream areas where cohort development and emergence were more synchronous because seasonal changes in water temperature were more pronounced and the summer maximum temperature was higher. Similarly, in thermally stable tropical streams without pronounced seasonality of flow. large and small individuals of all species tend to be present throughout the year (Bishop, 1973: Hynes, 1975). Where flow is more seasonal, cohort development tends to be more synchronous. Therefore, it appears broad SFD are a feature of stable environments which contradicts Hynes' (1970) suggestion that broad SFD may be insurance against extinction in unpredictable environments. Where SFD is controlled by environmental conditions any reduction in spatial overlap attributable to broad SFD maybe fortuitous. Fortunately, broad SFD are a feature of stable environments where competition is likely to be a more important determinant of distribution and abundance than are extrinsic factors such as discharge.
Muller (1954) hypothesized that drift acts to reduce competition for food and (or) space. Because drift is primarily a nocturnal activity, reduction of competition for space by drift should result in decreased spatial overlap at night. The highly variable and relatively small nocturnal changes in spatial overlap reported here do not support Muller's hypothesis.

\section{Summary}

To determine if broad size frequency distributions serve to reduce intraspecific competition for space, this study examined spatial niche breadth and overlap of size groups of four species of epilthic stream insects: Baetis intercalarls McDunnough, Paraleptophlebia mollis (Eaton), Glossosoma nigrior Banks and Chımarra aterrima Hagen. Over all species, most niche breadths for size groups colonizing artificial substrates (bricks) were between 0.50 and 0.90 because individuals occurred on all bricks but showed preferences for specific ones. For $B$. intercalaris and $P$. molls there were no consistent relationships between size of nymphs and niche breadth whereas for $G$. nigmor niche breadth increased with size and for $C$. aterrma niche breadth decreased with size. In most cases (7I\%) niche overlap among size groups of a species was $>1.0$ and of these $6 \mathrm{I} \%$ were $>1.20$ reflecting the unequal distribution of individuals a mong bricks but more importantlyshowing the preferences of the size groups coincided.

Mean niche overlap decreased with increased breadth of size frequency distribution (SFD) for only one species ( $B$. intercalaris) and did not vary in relation to population density. Over all size groups of all species, the probability of intergroup encounter between individuals was $10-40 \%$ less than the probability of intragroup encounter. However, the ratio of probabilities of intergroup and intragroup did not vary in relation to breadth of SFD. Because niche overlap and the ratio of probabilities of intergroup and intragroup encounter did not vary with breadth of SFD. it was concluded that changes in SFD have a min1mal effect on intraspecific competition for space among epilithıc species. SFD may be more important in regulating competition for space in cryptic species occupying interstitial spaces.

It was suggested that observed SFD may be more a function of extant environmental conditions (e.g., water temperature and flow) than of previous or extant intraspecific competition. 


\section{Acknowledgements}

These data were collected while the author was supported by a predoctoral fellowship and dissertation grants from the Rackham School of Graduate Studies, University of Michigan. Accommodations at the Pigeon River Station were kindly provided by the Michigan Department of Natural Resources. B. Krivak and S. Kovalak assisted with data collection and K. Walker and W. Dewalt assisted with analyses. Special thanks are due L. G. Klikoff, Allegheny College, Meadville, Pennsylvania, for his support of this work.

\section{References}

Bishop, J. E. I 973. Limnology of a small Malayan river, Sungai Gombak. Monogr. B1ol. 22: I-485.

Corkum, L. D. 1978. The influence of density and behavioural type on the active entry of two mayfly species (Ephemeroptera) into the water column. Can. J. Zool. 56: 1202-I 206.

Cummıns, K. W. 1975. Macroinvertebrates. pp. I70-198. In: River Ecology (B. A. Whitton, ed.) Univ. California Press, Berkeley.

Décamps, H., Larrouy, G. \& Trivellato. D. 1975. Approche hydrodynamıque de la microdistribution d'ınvertébrés benthiques en eau courante. Ann. Limnol. I I: 79-100.

Hurlbert, S. H. 1978 The measurement of niche overlap and some relatives. Ecology 59: 67-77.

Hynes, H. B. N. I96I. The invertebrate fauna of a Welsh mountain stream. Arch. Hydrobiol. 57: 344-388.

Hynes, H. B. N. 1970. The Ecology of Running Waters. Univ. Toronto Press, Toronto.

Hynes, J. D. 1975. Annual cycles of macro-invertebrates of a river in southern Ghana. Freshwat. Biol. 5: 71-83.

Ide, F P. 1935. The effect of temperature on the distribution of the mayfly fauna of a stream. Publ. Ont. Fish. Res. Lab. 50: I-76.

Kovalak, W P. 1975. Diel changes in the distribution and abundance of benthic stream insects. Ph.D. dissertation. Univ. of Mich., Ann Arbor, Mich.

Kovalak, W. P. 1976. Seasonal and diel changes in the positıoning of Glossosoma nigrior Banks (Trichoptera: Glossosomatidae) on artifical substrates. Can. J. Zool. 54: 1585-1594.

Kovalak, W. P. 1978a. Relationships between size of stream insects and current velocity. Can. J. Zool. 56: I78-I86.

Kovalak, W. P 1978b. On the feeding habits of Phasganophora capitata (Plecoptera: Perlidae). Great Lakes Entomol. II: 45-49.

Kovalak, W. P. I 979. Day-night changes in stream benthos density in relation to current velocity. Arch Hydrobiol. 87: I-I 8.

Levins, R. 1968. Evolution in Changing Environments: Some Theoretical Explorations. Princeton Univ. Press, Princeton.

Macan, T. T. 1963. Freshwater Ecology. J. Wiley \& Sons, Inc., New York.

Madsen, B. L. 1968. The distribution of nymphs of Brachyptera risi Mort. and Nemoura flexuosa Aub. (Plecoptera) in relation to oxygen. Oikos 19: 304-310.
McLay, C. I968. A study of drift in the Kakanui River, New Zealand. Aust. J. Mar. Freshwat. Res. I9: 139-I49.

Moretti, G. P. \& Gianottı, F. S. I962. Der Einfluss der Strömung auf die Verteilung der Trichopteren Agapetus gr. fuscipes Curt. and Silo gr. nigricornis Pict. Schweiz. Z. Hydrol 24: 467-484.

Muller, K. 1954. Investigations on the organic drift in North Swedish streams. Rep. Inst. Freshwat. Res. Drottnıngholm 35: I33-I48.

Roughgarden, J. 1972. Evolution of niche width. Amer. Nat. 106: 683-718.

Scott, D. 1958. Ecological studies on the Trichoptera of the River Dean, Cheshire. Arch. Hydrobiol. 54: 340-392.

Sheldon, A. L. I 969 . Size relationships of Acroneuria calıfornica (Perlidae, Plecoptera) and its prey. Hydrobiologia 34: 85-94.

Siegfried, C. A. \& Knight, A. W. 1976. Prey selection by a set1palpian stonefly nymph, Acroneuria (Calineuria) calıfornica Banks (Plecoptera: Perlidae). Ecology 57: 603-608.

Tındall, M. J. \& Kovalak, W. P. 1979. Food particle sizes consumed by larval Glossosoma nigrior (Trichoptera: Glossosomatidae). Great Lakes Entomol. 12: 105-108

Wallace, J. B. \& Malas, D. I 976 . The fine structure of capture nets of larval Philopotamidae (Trichoptera), with special emphasis on Dolophilodes distinctus. Can. J. Zool. 54: I 788-I 802.

Walton, O. E., Jr., Reice, S. R. \& Andrews, R. W. 1977. The effects of density, sediment particle size and velocity on drift of Acroneuria abnormis (Plecoptera). Oikos 28: 29I-298.

Williams, N. E. \& Hynes, H. B. N. I 973. Microdistribution and feeding of the net-spinning caddisflıes (Truchoptera) of a Canadian stream. Olkos 24: 73-84. 